\title{
AS NOVAS TÉCNICAS DE PESQUiSA EM COMUNICAÇÃo VISUAL: UMA PROPOSTA METODOLÓGICA DA VIDEOGRAFIA
}

\author{
Alba Marin \\ Departamento Comunicação Hipermédia, Universidade Savoie Mont Blanc, França \\ Fernando Contreras \\ Departamento de Jornalismo 1, Universidade de Sevilha, Espanha
}

\begin{abstract}
Resumo
O objetivo deste trabalho é mostrar a aplicação da videografia na pesquisa em comunicação e especificamente a proposta de um modelo metodológico para produções audiovisuais de não-ficção. Superados os debates sobre a fragilidade epistémica da antropologia audiovisual, podemos adotar essas ferramentas visuais caracterizadas pela diversidade de formatos e suportes à pesquisa social. Para o estudo do documentário, a interdisciplinaridade permite um trabalho flexível baseado na inter-relação de elementos das diversas disciplinas envolvidas. Propomos um modelo metodológico composto pela aplicação de análise visual, entrevista em profundidade e videografia para o estudo do documentário audiovisual. Aplicamos o plano metodológico a uma amostra de documentários em diferentes formatos. A natureza expandida ou imersiva dos documentários que analisamos levou-nos à criação de categorias de análise específicas para esses novos formatos como o interativo, o transmedia ou o imersivo. Além disso, introduzimos o vídeo em $360^{\circ}$ num de nossos estudos de caso para conhecer as suas possibilidades. $\mathrm{O}$ artigo fornece uma comparação entre os formatos de vídeo e uma reflexão teórica em torno do olhar do pesquisador e da natureza autorreferencial da pesquisa que compartilha o audiovisual simultaneamente como objeto e método.
\end{abstract}

\section{Palavras-chave}

comunicação; videografia; documentário; métodos visuais; metodologia

\section{THE NEW RESEARCH TECHNIQUES IN VISUAL COMMUNICATION: A METHODOLOGICAL PROPOSAL OF VIDEOGRAPHY}

\begin{abstract}
The aim of this paper is to show the application of videography in communication research. Having overcomed the debates on the epistemic weakness of audiovisual anthropology, we can adopt these tools characterized by the diversity of formats and supports for social research. For the study of non-fiction audiovisual production, interdisciplinarity allows flexible work based on the interrelation of elements of the various disciplines involved. We propose a methodological model composed of visual analysis, interview and videography for the study of audiovisual documentary. We have applied the method to a sample of documentaries and to three case studies of documentary productions in different formats. The expanded or immersive nature of the documentaries we analyse have led us to create specific categories of analysis for these new formats. Complementary we have introduced the $360^{\circ}$ video in one of our case studies
\end{abstract}


to know its possibilities. Among the results obtained we highlight the creation of a visual, textual and audiovisual material that provides us with information for the study of the documentary. The article fournishes a comparison between video formats and a theoretical reflection around the researcher's gaze and the self-referential nature of research that shares the audiovisual simultaneously as an object and method.

\section{KEYWORDS}

communication; videography; documentary film; visual methods; methodology

\section{INTRodução: uma PERSPETIVA AUdiovisual PARA O ESTUdo da COMUNICAÇÃo}

A pesquisa em comunicação é um campo de estudo no qual devemos adaptar constantemente os métodos de pesquisa às formas emergentes de novos média. Num contexto em que as ações humanas e o ambiente sociocultural estão misturados com a tecnologia, devemos considerar o uso de técnicas de estudos visuais e meios digitais que possam ser complementadas com outras técnicas tradicionais de pesquisa em Ciências Sociais (como a análise de conteúdo ou a entrevista). Este trabalho mostra o registro da realidade com a tecnologia audiovisual como uma ferramenta útil para a pesquisa científica. Para isso, estudámos produções de não-ficção vinculadas a realidades alternativas, narrativas expandidas, participativas e móveis.

Entendemos o documentário como uma forma contemporânea de expressão audiovisual a meio caminho entre a criação artística e produções mediáticas, pelo que pode ser enquadrado no contexto dos estudos visuais (Bal, 2016; Brea, 2005; Canclini, 2010; Contreras, 2017). Os estudos visuais oferecem uma estrutura interdisciplinar que nos permite interrelacionar elementos das disciplinas envolvidas na criação audiovisual. Embora essas disciplinas não partilhem as mesmas metodologias, elas têm o mesmo objeto em comum. A teoria da comunicação é considerada uma "ciência encruzilhada" na qual várias ciências convergem (Rodrigo-Alsina, 1989, p. 113). O documentário encontra-se neste cruzamento em vários níveis. Estamos a falar de interdisciplinaridade porque o objeto de estudo é partilhado com outras disciplinas. Mattelart e Mattelart (1997) mostram-nos que "os objetos de estudo são muitas vezes impostos à investigação, em virtude dos métodos disponíveis, quando o que teria que ser feito é adaptar os métodos ao objeto" (Mattelart \& Mattelart, 1997, p. 57). A sua perspetiva é semelhante à proposta por Brea quando este afirma a necessidade de uma abordagem "poliédrica" para o estudo da comunicação (Brea, 2005, p. 13). Ambos os autores concordam nos seus argumentos sobre a escolha de uma metodologia que combine disciplinas, referindo-se especificamente à fundação de uma epistemologia do visual na comunicação.

Quanto ao objeto de estudo da pesquisa em que o modelo metodológico proposto foi utilizado, a inovação tecnológica motivou cada vez mais documentalistas, Nonny de la Peña, Brad Lichtesnstein e Jeff Fitzsimmons (Across the line, 2015); Gabo Arora y Chris Mikl (Clouds over sidra, 2015); Karim Bem-Khelifa (The enemy, 2017); Marcello Hopkins 
(On the brink of famine. Urgence au sud Soudan, 2017); Maria Court e Rosemarie Lerner (Proyecto Quipu, 2013-2019) a propor narrativas experimentais em espaços partilhados para inclusão de utilizadores. Pensar agora no processo criativo de um pós-documentário difere da conceção tradicional de documentário cinematográfico linear, pois a inclusão de outras técnicas, como a realidade virtual, faz com que a dinâmica da produção mude necessariamente. A conceção do documentário voltou-se para a imagem do pathos (Bal, 2016), em relação à sua função na experiência humana, bem como às possibilidades associadas à função narrativa da imagem por meio da inovação tecnológica. Nesse contexto, a exploração da prática documental para entender a visualidade contemporânea e a sua instrumentalização adaptada às demandas de um espectador diferente, são dois caminhos que levam a novos fenómenos da comunicação mediada pela tecnologia.

\section{A PESQUiSA EM COMUNICAÇÃo COM MÉTOdos VISUAIS}

Como explica Pauwels (2000), os métodos visuais estudam o que vemos e como damos sentido ao visual, a experiência de observação dos objetos visuais e a atribuição de sentido às representações visuais. Este autor acrescenta outra consideração fundamental no uso dos métodos visuais: "a aquisição de habilidades e conhecimentos necessários para produzir material visual como parte crucial do discurso científico" (Pauwels, 2000, p. 9).

A Revue Française des Méthodes Visuelles propõe uma definição de métodos visuais baseada numa tradição apoiada na pesquisa de imagens. Situa os métodos visuais numa estrutura de reflexão e prática de abordagem hermenêutica e heurística, a incursão da teoria crítica (Horkheimer \& Adorno, 2016) e uma constante autorreflexão. "Poderíamos definir superficialmente os métodos visuais como o conjunto de métodos de pesquisa em Ciências Sociais e Humanas que não se limitam à produção e/ou entrega de escritos em seus modos de argumentação científica" (Bouldoires, Meyer \& Reix, 2018, p. 11).

No exercício da etnografia visual e digital, os aspetos do pensamento crítico são muito cuidadosos. Os registos audiovisuais têm sido utilizados há anos em pesquisa etnográfica. O uso de softwares, dispositivos de fotografia e de vídeo, plataformas sociais ou aplicações móveis para análise qualitativa é atualmente reconhecido no campo académico e cada vez mais campos de conhecimento adotam essas inovações (Álvarez, Giraldo \& Navarro, 2017). A todas essas inovações tecnológicas na pesquisa científica do documentário, devemos acrescentar a necessidade de uma consciência comprometida e política que garanta conclusões críticas, necessárias após o registro visual. Se levarmos em conta o papel participativo do investigador, especialmente com o uso da câmara de vídeo como uma ferramenta de pesquisa, a dimensão ética adquire relevância especial, bem como o comprometimento com os seus objetivos de investigação.

A videografia está posicionada nos debates etnográficos mais amplos sobre como a objetividade e a subjetividade, e o apelo à formulação de etnografias como textos multivocais em vez de dados objetivos. A videografia compreende e usa o vídeo como uma ferramenta para reorientar o poder 
do olhar do pesquisador e dar voz aos sujeitos/participantes da pesquisa.

(Jewitt, 2012, p. 3).

A imagem surgiu nos primórdios da Antropologia, embora esta disciplina tenha sido um terreno académico tradicionalmente dominado pela palavra. A imagem constituía uma ferramenta da coleção da informação e não funcionava como um testemunho ou como um arquivo mnemotécnico. Atualmente, a aquisição sensorial dos principais sujeitos da pesquisa torna-se mais importante que a recolha sistemática de dados de forma descritiva.

Apesar do reconhecimento progressivo do valor do visual, só nos anos setenta do século XX a imagem será reconhecida academicamente (Dion, 2007). Isso apesar de o cinema científico ter um passado mais distante. Por exemplo, Foam Malinowski (18841942) e Flaherty (1884-1951) promoveram o cinema etnográfico expositivo. Na Antropologia Visual Descritiva destacaram-se Regnault, Meda e Bateson (Febrer, 2013, p. 728). $\mathrm{Na}$ década de 1950, a obra de Jean Rouch (1917-2004) inspirou uma nova geração de antropólogos que impulsionarão a antropologia visual contemporânea. No panorama atual, os métodos visuais estão totalmente reconhecidos (Pink, 2006) e os trabalhos interdisciplinares enriquecem-se mutuamente. Com o desenvolvimento tecnológico dos dispositivos de captação e a invenção de outras formas narrativas na interpretação das imagens, a pesquisa social progride estudando práticas audiovisuais que vão além de uma atividade artística baseada na fotografia e no vídeo (Ibanez, 2006).

Os métodos visuais são herdeiros da Antropologia Visual, o que significa que a imagem é estudada como objeto e o visual usado como método de pesquisa. Seria uma falta de visão considerar apenas a função da imagem e não a experiência do observador face ao objeto da sua investigação. Na Antropologia Visual, a imagem é um elemento intrínseco ao método de pesquisa, que atua independentemente da natureza do objeto que ela representa. Assim, a metodologia visual não se baseia na análise estilística para gerar conhecimento relacionado com o valor estético. Trata-se de uma investigação com imagens (Dion, 2007) que no nosso caso específico se complica, porque a aplicamos ao estudo do documentário. O visual é método, objeto de estudo e processo de criação de imagens através da imagem.

\section{A herança da Antropologia Visual e os média}

Parte da dificuldade de um estudo visual é a adaptação contínua do investigador à escolha de uma tecnologia de pesquisa apropriada. A investigação antropológica move-se para as comunidades virtuais. Isto conduziu à observação de comportamentos sociais na rede e à análise da atividade comunicativa mediada por dispositivos digitais. A etnografia virtual tem sido desenvolvida pela necessidade de adaptar métodos convencionais (etnografia física) aos objetos da cultura digital e da comunicação virtual.

Os média digitais ocupam um lugar central no nosso mundo. É através deles que nos relacionamos com os outros e até nos ajudam a entender-nos a nós mesmos. 
A câmara de vídeo coloca em imagem o próprio espectador, como o aparelho fotográfico já tinha feito. Mas, ao contrário deste, convida-o a comunicar com os outros através deste meio, ou a observar-se nele mesmo. Esta praxis já se tornou típica em filmes, quando os casais comunicam os seus sentimentos através de gravações ao vivo ou projetando-se mutuamente. Isso estabelece em mãos privadas um meio de presença que já não está restrito ao estado antigo de um meio de lembrança, e que também não está sujeito ao salto temporal que anteriormente separou todas as imagens de seu espectador. (Belting, 2007 p. 103)

Nos primeiros estudos sobre comunicação mediada pela tecnologia, foi necessário transportar os métodos tradicionais para o novo contexto técnico (Hine, 2005). Devido à contínua evolução tecnológica, essa adaptação ainda é necessária, assim como repensar o papel do investigador e o cenário em que a sua investigação se realiza. O trabalho de campo move-se para o contexto digital e o investigador entra nesse espaço virtual para procurar relações sociais e comportamentos individuais (Turkle, 1997).

A Antropologia dos Média estuda a comunicação usando ferramentas visuais ou digitais. No caso de análise do filme de não-ficção, a Antropologia dos Média utiliza na investigação os mesmos procedimentos que intervêm na produção do objeto investigado: o observador encontra-se no observado. Analisamos o filme de não-ficção produzindo outro filme.

Dickey (1997) e Spiltunikn (1993) têm defendido a pesquisa antropológica em estudos dos média e, especificamente, nos processos de representação e construção de imaginários. A partir de novas interrogações sobre os média na década de 1990, a Antropologia Visual foi legitimamente integrada na investigação em comunicação para explicar as reações do público aos meios de comunicação (Dickey, 1997, p. 4).

A Antropologia dos Meios de Comunicação centra-se nas relações entre os jornalistas e as fontes, as relações humanas que rodeiam o trabalho de informação e o estudo de contextos e formas de receção. A etnografia virtual, que desenvolve o seu trabalho na internet, provoca a deslocalização total do campo de trabalho, a dissolução do espaço de estudo e a realocação do investigador. Em suma, o seu trabalho é desenvolvido nos novos cenários criados pelas tecnologias digitais. De acordo com Lemos (2008) não se trata de um confronto entre o "virtual" e o "real", mas da migração da produção social de sentido de um espaço criado pelas redes, no qual intervêm as experiências de lugares físicos, objetos e pessoas reais.

Para o estudo da comunicação, Goodwin $(1993,2000)$ destaca a observação dos fenómenos visuais e dos processos de criação de significados. A gestualidade e a sua gravação em documentos visuais ajudam a compreender as realidades sociais. No seu trabalho, a análise não se concentra em eventos visuais isoladamente, mas nas práticas sistemáticas utilizadas pelos participantes na interação. Com a sua maneira de analisar é possível ir além das relações interpessoais das práticas audiovisuais no conhecimento de uma comunidade. 
A comunicação mediada por computador e o reconhecimento académico da cibercultura, ajudaram a introduzir a versatilidade metodológica na etnografia (Hine, 2005). Exemplos incluem o trabalho de Flores-Márquez sobre o ativismo digital (2015); a União de territórios físicos e virtuais (Lemos, 2008), o trabalho de Edgar Gómez Cruz sobre a autorrepresentação (Gómez Cruz, 2012) ou o projeto "Selfiestories e dados pessoais: metodologias híbridas para a análise de narrativas visuais na cultura digital"'.

A partir do modelo de antropologia pós-moderna (Dion, 2007; Geertz, 1992), a noção de objetividade muda com relação à investigação e uso da imagem. A utilização e produção de imagens era então considerada uma negociação construtiva entre os sujeitos e o investigador. Jean Rouch (1995) assume a transformação do papel tradicionalmente desempenhado pelo investigador, a câmara e a imagem apresentada, a interpretação e a participação do investigador como parte da própria pesquisa. Sarah Pink (2001) analisou os vários usos possíveis de vídeo em Antropologia. Nem todos os investigadores o empregam da mesma forma, como alguns que pretendem produzir vídeos editados. Pink defende a dimensão subjetiva da imagem que fornece uma reflexão sobre as experiências sensoriais. Isto é possível a partir da filmagem, uma vez que a imagem tem a capacidade de evocar sensações corporais de uma forma diferente da palavra. O vídeo não é apenas uma via para a recolha de dados, mas uma ciência aplicada que participa da negociação das relações sociais, um meio que gera conhecimento para a Etnografia (Pink, 2001, p. 138).

Nas abordagens originais de Rouch (1995), a câmara deixa de ser um objeto distante para se integrar como um participante na ação documental. A extração de conhecimento emerge desta imersão da câmara e do observador naquilo que é observado. Anteriormente, só se contemplava, e o observador tomava notas para explicar as ações do grupo. Era desta forma que validava os dados. Atualmente, o observador mergulha com a câmara como um participante do fenómeno social para obter informações a partir da colaboração e da interação. Uma colaboração provocada em algumas ocasiões quando o processo de criação de imagens é oferecido aos sujeitos para se autorrepresentarem, ou também para interagirem com imagens que lhes são mostradas, se estas já tiverem sido gravadas anteriormente.

Para esta reflexão recorremos ao campo da Antropologia Visual num ambiente tecnológico como Bancks e Morphy (1997); Banks e Ruby (2011); Collier e Collier (1986); Hine (2005, 2015); Hockings (1995); Ibanez, Chabert, Lamboux-Durand e Wanono (2017); Pink (2001, 2006); Rouch (2003); Ruby (2000). Estes autores avançaram na narrativa documental com a utilização combinada de fotografia e vídeo em trabalhos iniciais, e depois com a hipermédia e o uso de diferentes dispositivos tecnológicos. Além disso, aperfeiçoaram a integração das tecnologias visuais e digitais no estudo etnográfico, de entre os quais podemos destacar a hipermédia (Ibanez, 2006).

O papel do observador e a sua ligação com a câmara determina a relação que é construída com a realidade e, neste caso, com o objeto de estudo. Lallier (2009) considera mais relevante a relação entre o filmado e quem filma na investigação e a utilização

\footnotetext{
' Informação sobre o projeto disponível em https://selfiestories.net
} 
do movimento e do espaço no filmado e em quem filma: "a sequência filmada procede da relação social entre aquele que observa-filma e as pessoas filmadas" (Lallier, 2011, p. 107). Segundo Lallier (2011), a etnografia filmada é diferente daquela que é escrita, uma vez que a reciprocidade com a situação estudada é muito estreita. O etno-cineasta envolve-se, participa da ação, não permanece como um elemento estranho que não intervém; há um envolvimento pessoal do investigador com o evento ou situação observada. Lallier denomina esta prática de observação filmada. Com isso define um tipo diferente de prática para o campo da pesquisa social, assim como o faz a observação participante.

\section{Proposta de UM Modelo Metodológico aUdiovisual interativo PARA A INVESTigaçÃo SOBRE O DOCUMENTÁRIO AUDIOVISUAL}

A nossa proposta de modelo metodológico visual é baseada na triangulação das seguintes técnicas complementares: análise visual, filmagem participante e entrevistas em profundidade. $\mathrm{Na}$ abordagem etnográfica, a triangulação é comum: observação, entrevistas, análise de documentos e outras formas de recolha de dados combinadas (Flick, 2015). Segundo o autor, os estudos de caso são frequentemente realizados em investigações etnográficas nas quais vários métodos e dispositivos são utilizados para a recolha de dados. Projetámos este modelo metodológico para o estudo do documentário e aplicámo-lo em três estudos de caso que se encontravam na fase de produção. Em todos os três casos utilizou-se o vídeo como ferramenta de investigação para gravar diretamente diferentes estágios criativos durante a produção de documentários, bem como o resultado final entre o que foi filmado e a interpretação obtida da representação. Para completar a triangulação, realizámos entrevistas aprofundadas com os realizadores dos três documentários. O objetivo desta última técnica era aceder a informações que só poderíamos obter através de relações diretas com os criadores. Eles forneceram informações subjetivas e sem contaminação por outros fatores externos sobre a sua maneira de entender o processo criativo, a sua opinião sobre as contribuições das tecnologias de acordo com a sua experiência profissional e uma reflexão acerca do sucesso comunicativo em relação à representação e ao representado. Para isso, baseamo-nos principalmente nos trabalhos de Bruhn (2002), Flick (2011, 2015) e Mann (2016), sobre a entrevista como método de investigação em comunicação.

A etnografia é uma abordagem para estudar grupos e processos no seu ambiente natural, o que requer um uso flexível de métodos e muita paciência no campo. Os dados podem ser menos sistemáticos do que em outros métodos, mas podem ser mais holísticos nas descrições que tornam possíveis. Portanto, a generalização aqui é geralmente mais interna - no contexto - do que fora dos locais e campos em estudo. (Flick, 2015, p. 130)

No esboço da Figura 1, é possível ver como aplicamos a combinação desses métodos, com os quais conseguimos abordar o nosso objeto de estudo a partir de três perspetivas distintas: o trabalho final, a construção da representação e o ponto de vista do autor. 


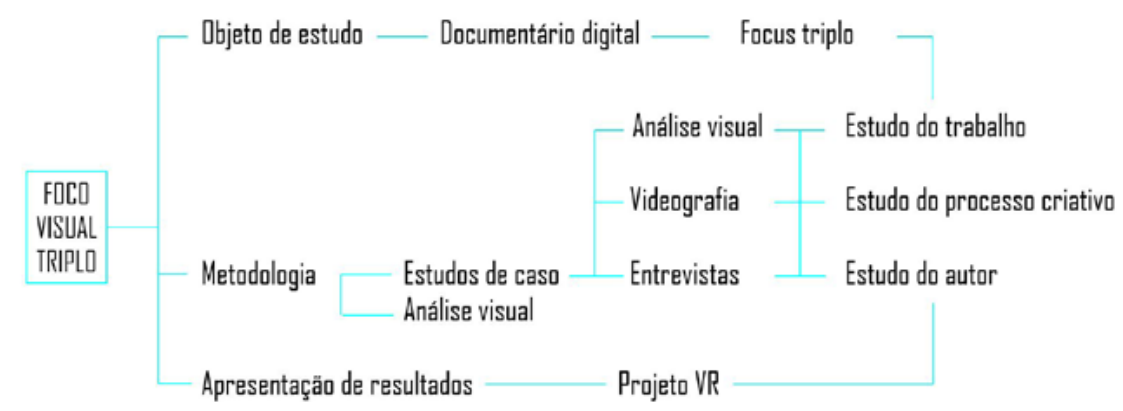

Figura 1: Esquema de triangulação metodológica e as abordagens de cada método ao objeto de estudo Créditos: Alba Marín e Fernando Contreras

Os estudos de caso foram selecionados de acordo com as suas características formais e a sua capacidade de se adaptarem aos requisitos temporais da nossa investigação. Entre os três casos, devem abranger os principais formatos digitais, a inclusão do usuário, seriados para permitir conhecer a qualidade de uma peça já publicada e estar na fase de produção de outro capítulo ou documentário da série.

O documentário La Primavera rosa (Mário de la Torre, 2016-2018) é concebido como um projeto transmédia com vários capítulos, dos quais quatro já haviam sido publicados e um quinto estava em andamento. Esses quatro capítulos tinham um elemento diferenciador que os tornava ideais para o estudo: um formato diferente em cada capítulo, de maneira complementar ao audiovisual linear.

O documentário Las sinsombrero (Tania Balló, Manuel Jiméze e Serrana Torres, 2015-2019) é um dos documentários de referência da produção espanhola nos últimos anos, devido à sua natureza ampliada e à inovação no seu formato, especialmente o $w e b d o c$ e o uso de redes sociais. Além disso, o seu webdoc inclui três níveis de interatividade que consideramos especialmente interessantes para analisar, pois não é comum encontrá-los no mesmo trabalho.

Hors-Cadre (Martín Charrière, 2017-2019) é uma série de não ficção em realidade virtual que atualmente possui quatro curtas-metragens e que usamos como exemplo de referência para o documentário imersivo, um subgénero ainda emergente.

\section{O FORMATO DO MODELO DE ANÁLISE VISUAL}

As perspetivas da história das imagens e dos meios só se justificam quando não se descartam mutuamente. A perspetiva visual da antropologia centra-se na praxis da imagem, que requer um tratamento diferente do das técnicas da imagem e sua história (Belting, 2007). A análise utiliza os estudos de caso que, na nossa pesquisa, consistiu numa amostra de documentários. Procurámos analisar os elementos que entram em jogo na criação do documentário audiovisual.

O modelo de análise requer inicialmente as categorias clássicas de filmes e as análises audiovisuais narrativas propostas por Barthes (2002, 2017); Belting (2007); 
Bordwell Casetti e di Chio (1991); Derrida e Stiegler (1998); Gaufreault e Jost (1995); Gifreu Castells (2013); Köster (2005); Nichols (2010) ou Plantinga (2014). Para concluir a proposta de análise, adicionamos categorias específicas das obras transmédia ou imersivas. Chegados a este ponto, ressaltamos que essa análise tem que ser feita a partir de um profundo envolvimento do investigador, uma vez que muitas das obras são imersivas, personalizadas ou participativas, e a análise é feita da experiência completa.

\begin{tabular}{lll}
\hline \multicolumn{1}{c}{ CATEGORIA } & \multicolumn{1}{c}{ DESCRIÇÃo NíVEL 1 } & DESCRIÇÃO NíVEL 2 \\
\hline Contexto & Descrição da obra & \\
& Sinopse & \\
& Dados técnicos & \\
\hline Categorias formais & Códigos visuais & Movimento \\
& Códigos gráficos & Composição \\
& Códigos de som & Nementos textuais \\
& & Natureza e utilização do som \\
\hline Categorias da representação & Serialização (set up) - montagem & \\
& Composição do espaço & \\
\hline Dimensões da narração & Composção da temporalidade & \\
& Marcas de enunciação & \\
\hline Inclusão do espetador & Estrutura do relato & \\
& Ponto de vista /ocularização & \\
& Interatividade & \\
\hline Expansão do relato & Participação & \\
\hline Relação meio/imagem/utilizador & Personalização & \\
\hline Descrição final da experimen- & Imersão & \\
tação pessoal da obra & Níveis e natureza & \\
\hline
\end{tabular}

Tabela 1: Modelo de análise para o pós-documentário

\section{COMO APLICAR A VIDEOGRAFIA NUM CASO PRÁTICO DE INVESTIGAÇÃo}

Durante os dias de gravação da produção de documentários, introduzimos a câmara de forma interativa. Essa interação foi destinada a tirar proveito daqueles resultados que só podem ser fornecidos por uma observação participante. Para isso, a câmara e o processo de filmagem foram integrados na mesma produção do documentário que estudámos (Rouch, 2009). Procurámos também incorporar a abordagem antropológica visual de Lallier (2011) e a sua observação filmada:

a observação filmada não consiste simplesmente em observar com uma câmara, como se a utilização de um dispositivo por si só determinasse uma prática de campo. (...) De fato, a observação filmada não pertence a uma escrita propriamente dita ou a uma simples técnica de registro, mas a uma prática social: uma forma única de lidar face a face com o objeto da nossa representação. (Lallier, 2011, p. 105) 
Por sua parte, Jewitt (2012) estabelece uma diferenciação na aplicação de vídeo à investigação, distinguindo entre vídeo participativo e videografia. O vídeo participativo é um processo de intervenção no qual os participantes têm acesso a ferramentas de gravação e/ou edição para criar a sua própria visão do objeto de estudo. Na aplicação da videografia, encontramos formas colaborativas de pesquisa muito próximas de documentários colaborativos e formas individuais mais próximas do diário filmado.

A videografia é geralmente usada para aprofundar questões culturais e sociais através da criação audiovisual: seja desde a antropologia visual (Collier, 1995; Collier \& Collier, 1986) ou desde o documentarismo (Cyrulnik, 2018). A recente pesquisa de Stollbrock (2017) sobre memória e representação no documentário é um exemplo da aplicação mais difundida de técnicas visuais. O documentário La Siberia (Sierra \& Stollbrock, 2015) serviu ao seu autor para desenvolver uma investigação a posteriori sobre a representação temporária a partir do seu documentário realizado numa fábrica de cimento na Colômbia. O projeto etnográfico, neste caso sobre a memória e representação corporal da mulher afro-venezuelana, de Vila Guevara (2017) é outro exemplo semelhante de um processo de pesquisa culminando na criação do documentário Belén (Vila Guevara, 2017). Ambos os casos nos mostram a atual aplicação de documentário audiovisual ou da videografia na pesquisa social.

A nossa proposta centrou-se na continuidade do estudo dos processos comunicativos aplicando metodologias visuais. A figura do realizador-investigador é prevalente na Antropologia Visual como argumentámos, bem como no campo da investigação-criação, associada principalmente à investigação artística.

Através das filmagens no trabalho de campo foram registadas uma série de ações que posteriormente foram interpretadas graças à análise comunicativa e também à criação da obra derivada que se produziu como resultado da pesquisa. Coincidimos com Cordido (2010) sobre a contribuição dos postulados da Antropologia Visual sobre o registro audiovisual para captar símbolos, formas e relacionamentos no âmbito cultural. Esta contribuição baseia-se na integração do método desde o início do trabalho de campo até à exposição dos resultados, após a análise do material obtido. O processo envolveu a passagem dos dados gravados para a sua interpretação por meio da união entre a explicação teórica e a construção de um discurso audiovisual.

\section{CONSIDERAÇÕES ANTERIORES PARA A INTRODUÇÃo E UTILIZAÇÃo DO VÍDEO $360^{\circ}$ EM INVESTIGAÇÃ̃O}

Para melhorar a metodologia propomos de forma complementar e emergente o uso de vídeo $360^{\circ}$ como um dispositivo de gravação na nossa observação participante registada. Para a sua introdução, seguimos as etapas apresentadas na Tabela 2. 


\begin{tabular}{l}
\hline \multicolumn{1}{c}{ ETAPAS PARA A INTRODUÇÃO DO VíDEO } \\
\hline Entrevistas prévias e autorizações de gravação \\
\hline Inquérito sobre o dia para gravar e o terreno de observação \\
\hline Definição de horários, locais e material técnico: plano de gravação \\
\hline Objetivos específicos \\
\hline Jornada de gravação \\
\hline ETAPAS POSTERIORES À GRAVAÇÃo \\
\hline Fichas de registo \\
\hline Visualização, análise e categorização da informação \\
\hline Redação de relatórios finais \\
\hline Montagem do material e criação de trabalhos derivados \\
\hline
\end{tabular}

Tabela 2: Fases para a introdução e aplicação de videografia

\section{CONSIDERAÇÕES TÉCNICAS: A EQUIPA AO SERVIÇO DA INVESTIGAÇÃO}

Acreditamos que a equipa técnica e humana deve adaptar-se às necessidades específicas de cada investigação: mobilidade, adaptabilidade e discrição. Mesmo se usarmos a câmara interativamente não se trata de acumular a atenção. Portanto, ferramentas simultaneamente discretas e funcionais têm sido as adequadas no nosso caso. Insistimos na importância das ferramentas, pois afetam diretamente o trabalho do investigador e as informações obtidas.

A seleção dos dispositivos de gravação deve ser adaptada à situação de cada estudo de caso, aos objetivos da pesquisa e às capacidades técnicas do investigador/produtor. Se continuarmos na ideia da câmara como uma extensão do corpo, como um dispositivo que aumenta as capacidades de observação do fenómeno, é crucial aceitar que o equipamento não deve, em nenhum caso, ser um problema. Ou seja, a melhor ferramenta será aquela que não distrai o investigador para que ele possa concentrar-se no objeto de estudo e não no bom funcionamento dos dispositivos. Para atingir esse objetivo, propusemos uma série de requisitos associados ao equipamento técnico a levar em conta para o bom desenvolvimento do trabalho de campo (Figura 2).

A câmara grava de maneira pessoal, como uma prótese que se adapta ao investigador para estender o seu olhar. Para fazer isso, decidimos dispensar os instrumentos de estabilização ou de apoio da câmara. Não consideramos necessário usar uma câmara fixa para um registo completo, pois o uso do vídeo não corresponde ao método observacional. Por outro lado, a figura do investigador com uma câmara na mão traz maior liberdade de movimento, acompanhamento das personagens e uso sensível do equipamento como registo da observação participante e do olhar do investigador. Pensamos numa integração mais orgânica, tanto para o investigador, já que pode "olhar através do alvo", quanto para os assuntos observados, que se habituaram a essa pessoa a olhar através da câmara como uma atitude natural. Para além disso, num dos casos de produção de documentário, incluímos a filmagem em $360^{\circ}$ que, como explicamos a seguir, pode oferecer a complementaridade da gravação a partir de um ângulo maior. 


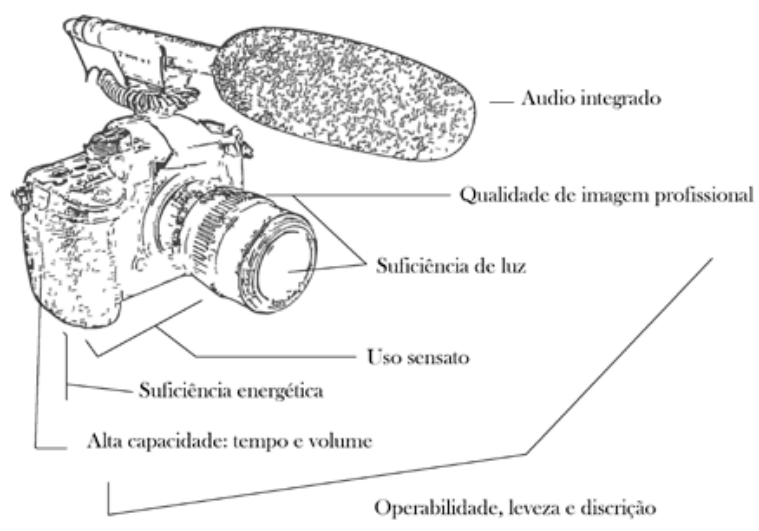

Figura 2: Características básicas do equipamento técnico Créditos: Alba Marin

No que respeita ao áudio, optou-se por um microfone de canhão embutido na câmara com bateria independente e duradoura. Este som foi completado com um segundo registo de áudio independente no gravador de mão para garantir a gravação. Selecionámos estes instrumentos seguindo às mesmas premissas da seleção do equipamento visual.

Finalmente, no que toca ao equipamento de iluminação técnica e outros acessórios, não valorizamos a iluminação artificial de qualquer tipo por duas razões: (a) implicaria outro elemento de distração que iria prejudicar a situação a observar; e b) estaríamos a poluir a cena com luz artificial e com tudo o que isso pode implicar em termos de invasão da cena.

\section{Planear as filmagens}

Embora estejamos perante um filme prospetivo, há uma série de perguntas que devemos colocar antes de realizar o trabalho de campo e aplicar o método visual. Que objetivo se procura com o registo? Onde vai ficar a câmara ou quem vai operá-la? Qual é o papel do investigador no processo? Qual é o papel que a câmara desempenha em relação às pessoas no estudo de caso e às ações? Qual é o ponto de vista do investigador para a gravação? Para que finalidade será utilizado o material registado e como é que cumpre os requisitos científicos da metodologia aplicada?

Contamos com o valor acrescentado da captura de espaço-tempo do fenómeno observado, mantendo a sucessão cronológica de eventos e o registro de gestos, palavras e sons. Estes elementos secundários, que podem parecer insignificantes a princípio, poderiam posteriormente tornar-se elementos indispensáveis ao processo que estudamos e ficaram registados para nosso benefício. Finalmente, com o que já foi obtido, é possível proceder ao cruzamento dos dados gravados, das observações não gravadas, das entrevistas exploratórias, das anotações e das entrevistas em profundidade. 


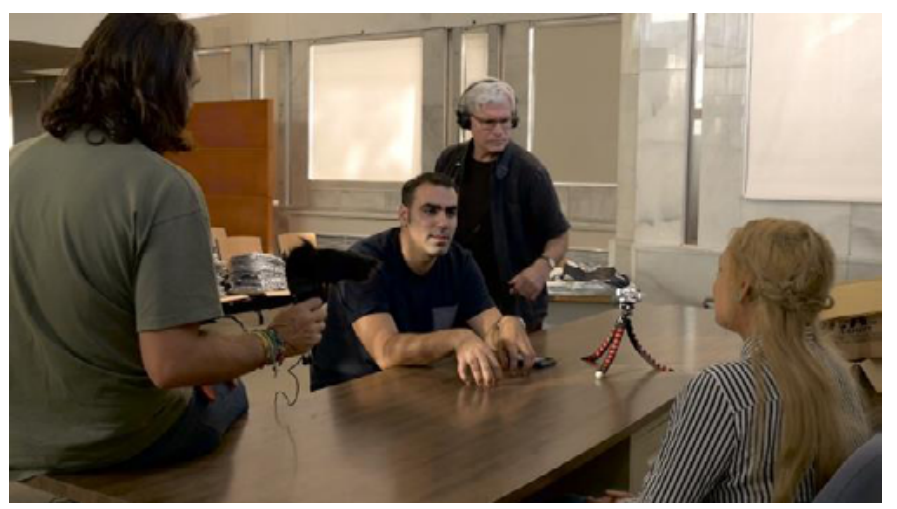

Figura 3: Quadro da gravação durante o trabalho de campo no nosso estudo de caso do documentário La Primavera rosa

Créditos: Alba Marín

No seu conjunto, o uso do vídeo permite que o investigador cumpra um papel participativo. Durante o nosso estudo do documentário na fase de gravação, La Primavera rosa (de la Torre, 2016-2018), realizámos um trabalho de campo que nos permitiu integrar como parte da equipa de produção. Neste cenário, usámos a câmara como um elemento natural incluído na cena que se produzia no documentário e não como uma ferramenta de recolha de dados externos.

\section{DESCRIÇÃO DOS CASOS ESTUDADOS COM A ABORDAGEM VIDEOGRÁFICA PROPOSTA}

As fases de produção dos documentários sobre os quais realizamos o trabalho de campo não obedeceram a uma escolha aleatória, foram selecionadas de acordo com os imperativos da produção de cada documentário. Em cada documentário filmamos uma fase diferente do processo que, em conjunto, nos permitiu ter uma visão geral da produção da representação.

Durante a etapa de filmagem observámos e registámos o processo de produção que engloba a seleção de imagens na produção, a entrevista completa e o trabalho dos documentários antes, durante e após o processo. Aqui observámos que é então que tem lugar uma parte importante da construção da representação, já que a partir desse momento se está a fazer uma seleção do que se grava. Além disso, quando pudemos gravar a última entrevista, os documentaristas tinham uma ideia prévia do que queriam obter e uma aproximação ao resto do material audiovisual que já tinham gravado.

A partir da análise da nossa observação registada, fizemos uma comparação entre o tratamento da realidade durante as filmagens e a representação final dessa realidade que aparece no trabalho final. Além das gravações, foram realizadas pequenas entrevistas exploratórias com os participantes durante o trabalho de campo, para conhecer aspetos concretos da produção do documentário. Entrevistas exploratórias na fase de 
produção são cruciais para saber o porquê do posicionamento da câmara, a realização da sequência, o interesse que o diretor tem em cada protagonista, etc.. Ao interagir com a equipa de produção, a fim de obter mais informações, conseguimos contrastar as respostas com o observado e gerar mais conteúdo a partir do qual obter informação para as nossas conclusões. No que se refere à fase de pós-produção, foram igualmente cruciais as entrevistas exploratórias para obter informações pormenorizadas sobre a estrutura transmediática ou o objetivo que perseguem com cada decisão.

\begin{tabular}{|c|c|c|c|}
\hline CASO & FASE DE APLICAÇÃO & EQUIPA DE IMAGEM & EQUIPA DE SOM \\
\hline La Primavera rosa (2016-2018) & $\begin{array}{l}\text { Produção. Gravação da últi- } \\
\text { ma entrevista do capítulo } L a \\
\text { Primavera rosa em Espanha }\end{array}$ & $\begin{array}{l}\text { Câmara de vídeo mirrorless com } \\
\text { uma objetiva } 50 \mathrm{~mm} \text { de focal } \\
\text { fixa, operada pelo investigador }\end{array}$ & $\begin{array}{l}\text { Equipa de áudio } \\
\text { independente }\end{array}$ \\
\hline $\begin{array}{l}\text { Las sinsombrero } \\
(2015-2019)\end{array}$ & $\begin{array}{l}\text { Pós-produção. Jornada de } \\
\text { edição do segundo documen- } \\
\text { tário Ocultas e impecables }\end{array}$ & $\begin{array}{l}\text { Câmara de vídeo mirrorless com } \\
\text { uma objetiva } 50 \mathrm{~mm} \text { de focal } \\
\text { fixa, operada pelo investigador }\end{array}$ & $\begin{array}{l}\text { Equipa de áudio } \\
\text { independente }\end{array}$ \\
\hline Hors-Cadre (2017-2019) & $\begin{array}{l}\text { Pós-produção do capítulo } \\
\text { Intimités e etapa de con- } \\
\text { ceção do capítulo Holder }\end{array}$ & $\begin{array}{l}\text { Câmara de vídeo mirrorless com } \\
\text { uma objetiva } 50 \mathrm{~mm} \text { de focal fixa, } \\
\text { operada pelo investigador e câmara } \\
\text { Samsung } 360^{\circ} \text {, fixa sobre tripé }\end{array}$ & $\begin{array}{l}\text { Equipa de áudio } \\
\text { independente }\end{array}$ \\
\hline
\end{tabular}

Tabela 3: Aplicação da videografia aos três estudos de caso

Com o trabalho de campo, não só obtivemos imagens, como também conseguimos os dados da própria experiência e registámos as impressões que mais tarde seriam cruzadas com o material gravado. As três linhas de trabalho metodológico que desenvolvemos foram inseparáveis umas das outras na prática. A gravação, as entrevistas e a observação direta realizaram-se ao mesmo tempo, sobrepondo-se umas às outras de forma coerente. Deve-se acrescentar que não nos deparámos com um método totalmente estruturado. As entrevistas exploratórias do trabalho de campo não foram premeditadas, nem a localização da câmara em cada momento, porque não existe um roteiro sobre as ações dos documentaristas em todas as etapas. É o investigador que, desde o estabelecimento dos objetivos da metodologia, coloca em prática o processo de acordo com a forma como os eventos se desenvolvem durante o trabalho de campo. Neste cenário em constante transformação, o investigador de etnografia videográfica participa, interage e decide o que registar e com quem conversar.

\section{O víDEO EM $360^{\circ}$ COMO UMA FERRAMENTA DE PESQUISA}

A introdução do formato audiovisual imersivo responde principalmente ao interesse em experimentar as possibilidades oferecidas por essa ferramenta visual. $\mathrm{O}$ vídeo de 360 graus possibilita a análise da experiência de interação com o espaço, mediante outras sensações do corpo e os seus movimentos numa experiência imersiva. Um exemplo que nos mostra as possíveis aplicações de trabalhos imersivos em pesquisa de comunicação é o projeto de investigação "Réalités impossibles" (Chabert \& Groupierre, 2018), onde se experimentam e analisam as capacidades desses dispositivos em relação com os espaços. 
O vídeo de 360 graus altera a dinâmica convencional da narrativa audiovisual, pois obriga a criar uma história sujeita às sensações que o utilizador mais tarde perceberá a partir da imagem. Neste formato filma-se um plano subjetivo que deve ser pensado para que seja posteriormente visualizado e analisado pelo investigador, não para um utilizador externo a quem é contada uma história. Se usarmos esta câmara de vídeo em $360^{\circ}$ num espaço onde uma dada ação ocorre, podemos filmar a ação de todos os ângulos, se se colocar a câmara num ponto central. O investigador que utiliza o vídeo deve escolher o seu enquadramento, o ponto de foco e, finalmente, onde fixar o seu olhar. Durante este processo, inevitavelmente deixará de filmar outra situação que pode ser interessante. Este problema pode desaparecer ou, pelo menos, diminuir com a incorporação de vídeo de 360 graus. Abaixo encontra-se um breve relato das características técnicas de dois formatos de gravação e a comparação entre esses dois instrumentos aplicados à pesquisa.

\begin{tabular}{|c|c|c|}
\hline & VÍDEO $<180^{\circ}$ & VÍDEO $360^{\circ}$ \\
\hline Registo & $\begin{array}{l}\text { Gravação sensível/à mão } \\
\text { Planos fixos e planos em movimento } \\
\text { Ângulo máximo de } 180^{\circ} \text { variável } \\
\text { Seleção de planos e variedade }\end{array}$ & $\begin{array}{l}\text { Gravação independente } \\
\text { Plano fixo } \\
\text { Ângulo de } 360^{\circ} \\
\text { Limites na variedade de planos } \\
\text { Limitação da seleção para a cena }\end{array}$ \\
\hline Visualização e análise & $\begin{array}{l}\text { Visualização não imersiva } \\
\text { Registo = visualização } \\
\text { Possibilidade de visualização coletiva } \\
\text { Enquadramento variável selecionado pelo } \\
\text { investigador invariante na visualização }\end{array}$ & $\begin{array}{l}\text { Visualização imersiva } \\
\text { Registo diferente da visualização } \\
\text { Visualização individual } \\
\text { Quadro variável na visualização }\end{array}$ \\
\hline Papel da câmera & $\begin{array}{l}\text { Observação } \\
\text { Interação }\end{array}$ & $\begin{array}{l}\text { Observação } \\
\text { Registo descritivo }\end{array}$ \\
\hline $\begin{array}{l}\text { Relação } \\
\text { câmera-investigador }\end{array}$ & $\begin{array}{l}\text { Relação direta } \\
\text { Câmara como extensão do } \\
\text { olhar do documentarista } \\
\text { Gravação orgânica } \\
\text { Documentarista fora de campo }\end{array}$ & $\begin{array}{l}\text { Relação complementar } \\
\text { Utilização independente } \\
\text { Documentarista no enquadramento }\end{array}$ \\
\hline Mobilidade & Voluntária & Fixa. Sem mobilidade \\
\hline $\begin{array}{l}\text { Interação com os } \\
\text { protagonistas }\end{array}$ & $\begin{array}{l}\text { Ligada à filmagem } \\
\text { Desde fora de campo }\end{array}$ & $\begin{array}{l}\text { Independente } \\
\text { Dentro da cena }\end{array}$ \\
\hline
\end{tabular}

Tabela 5: Comparação das características de ambos os registros como ferramenta de pesquisa

Nos nossos estudos de caso, o vídeo de 360 graus teve um uso complementar à gravação da câmara de vídeo à mão. Isso fez com que o investigador-videógrafo aparecesse como um elemento da cena na imagem gravada em 360 graus. 


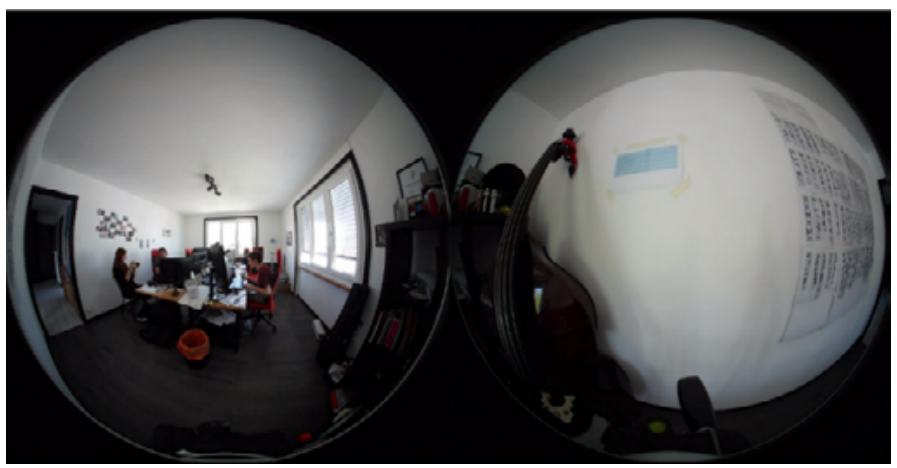

Figura 2: Fotograma de vídeo $360^{\circ}$ durante o estudo de caso Hors-Cadre (Charrière, 2017-2019) Créditos: Alba Marín

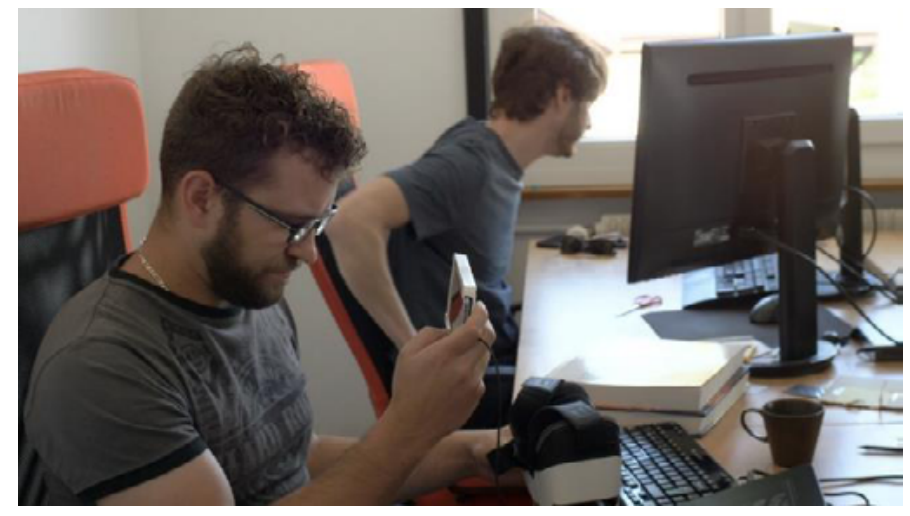

Figura 3: Fotograma do vídeo realizado durante o estudo de caso Hors-Cadre (Charrière, 2017-2019) que corresponde à gravação que pode ser vista na Figura 2

Créditos: Alba Marín

A partir das nossas diretrizes metodológicas, o investigador assume, inevitavelmente, um papel ativo e, portanto, não vemos nenhum inconveniente na sua presença na imagem. No entanto, estamos cientes de que é uma prática que deve ser considerada em cada estudo de caso, se ele desempenha um papel na pesquisa. A presença do dispositivo por si só altera o que se filma e, esteticamente, não devemos esquecer que o objetivo principal responde aos critérios de pesquisa.

\section{EM MODO DE CONCLUSÃO}

Propusemos uma abordagem etnográfica baseada no uso da videografia. Este modelo aborda a complexidade das produções audiovisuais na recolha de informações e na documentação da pesquisa social. Especificamente, a nossa metodologia foi projetada para a investigação do processo criativo de documentários. Para elaborar esta proposta, tivemos que reconhecer fatores diferentes a outras metodologias como a inclusão do investigador na realização de material audiovisual etnográfico, os novos 
modos narrativos da narrativa científica audiovisual ou o movimento do espectador em contextos imersivos.

A utilização de uma abordagem etnográfica na comunicação, o conhecimento dos meios audiovisuais e o trabalho articulado com dados de natureza diferente (imagem, áudio, vídeo, texto) aumentam a riqueza das informações obtidas no estudo do documentário. A essa metodologia, integramos os estudos de caso e a interação com os sujeitos da pesquisa. Ao mesmo tempo em que obtivemos e registámos os dados para o estudo do documentário utilizando uma abordagem antropológica, conseguimos material para criar um trabalho audiovisual como parte do mesmo processo produtivo. $\mathrm{O}$ resultado é uma investigação caracterizada pelo elemento "meta", uma vez que se trata do olhar do investigador através da imagem sobe uma obra audiovisual. A produção realizada como parte da pesquisa inclui um protótipo de criação audiovisual.

A incorporação das complexidades associadas à polissemia da visualidade pressupõe um desafio para os pesquisadores de comunicação que devem ter o treino ideal para aproveitar as possibilidades dessas ferramentas. Confrontamo-nos com a dificuldade de sistematização dos métodos audiovisuais, derivada da personalização associada ao seu uso e à falta de formação audiovisual como instrumento de investigação social. Consideramos, portanto, que, embora não estejamos numa linha inexplorada, é preciso mais desenvolvimento destes aspetos para a investigação em comunicação.

Experimentámos a incorporação do vídeo de 360 graus na investigação. Ainda falta definir o seu verdadeiro protagonismo em futuras pesquisas sobre comunicação. As características técnicas do dispositivo sugerem o seu uso complementar à câmara de vídeo de no máximo 180 graus. Os dados obtidos através de ambos os registos não se repetem, porque o modo de uso e a visualização respetivos possuem características diferentes que os tornam complementares. Depois de uma primeira experiência com este dispositivo, consideramos interessante continuar a via da exploração e da experiência em situações distintas para encontrar o contexto certo do seu uso.

A análise de um material filmado abre a investigação científica a ambientes imersivos. O que implica desenvolver outras metodologias de trabalho que se concentrem não apenas no tempo de obtenção dos dados e na interação com os sujeitos envolvidos, mas na análise subsequente da imagem. Uma análise dos dados recolhidos em vídeo inclui os seus próprios procedimentos particulares. No nosso estudo, a principal qualidade do vídeo de 360 graus num trabalho de campo etnográfico não reside no momento da filmagem, mas na sua visualização e análise. Com o processo de montagem correto, o investigador pode retornar ao espaço filmado e estudar diferentes elementos e momentos em paralelo. A fase de revisão assume uma nova dimensão, uma vez que o investigador não volta ao seu próprio olhar no registo audiovisual, mas o seu olhar volta ao palco. Embora seja verdade que nos deparámos com as limitações de exploração e de movimentos de vídeo, devemos valorizar neste tipo de trabalho científico: a relação entre o dispositivo tecnológico e o investigador, a temporalidade da realidade e o tempo da máquina, o espaço de trabalho e o espaço de análise, o papel da câmara e o papel do investigador. 


\section{REFERÊNCIAS}

Álvarez, G. M., Giraldo, M. \& Navarro, C. (2017). Uso de TIC en investigación. Katharsis, 23, 239-258. https:// doi.org/10.25057/25005731.873

Arora, G. \& Mikl, C. (Realizadores). (2015). Clouds over sidra [Documentário-web]. EUA: Within.

Bal, M. (2016). Tiempos trastornados: análisis, historias y políticas de la mirada. Madrid: Akal.

Balló, T., Jiménez, M. \& Torres, S. (Realizadores). (2015-2019). Las sinsombrero [Documentário-web]. Espanha: RTV.

Banks, M. \& Morphy, H. (1997). Rethinking visual anthropology. Londres: Yale University Press.

Banks, M. \& Ruby, J. (2011). Made to be seen. Perspectives on the history of visual anthropology. Londres: The University of Chicago Press.

Barthes, R. (2002). II n'existe aucun discours qui ne soit une fiction. In R. Barthes. OEuvres complètes. IV libres, textes, entretiens 1972-1976 (pp. 385-387). Paris: Éd. du Seuil.

Barthes, R. (2017). Introduction à I 'analyse structurale des récits. Communications, 8, 1-27. Retirado de https://www.persee.fr/doc/comm_0588-8018_1966_num_8_1_1113

Belting, H. (2007). Antropología de la imagen. Buenos Aires: Katz.

Ben-Khelifa, B. (Realizador). (2017). The enemy [Filme-web]. França: Camera lucida productions.

Bordwell, D. (1996). La narración en el cine de ficción. Barcelona: Paidós.

Bordwell, D. \& Carroll, N. (1996). Post-theory. Reconstructing film studies. Londres: The University of Wisconsin Press.

Bouldoires, A., Meyer, M. \& Reix, F. (2018). Introduction. Méthodes visuelles: définition et enjeux. Revue Française des Méthodes Visuelles, 2, 9-17. Retirado de https://data.msha.fr/rfmv/rfmvo2/rfmvo2bouldoires-meyer-reix-2018.pdf

Brea, J. L. (2005). Estética, historia del arte, estudios visuales. Estudios Visuales, 3, 8-25.

Bruhn, K. (2002). A handbook of media and communication research. Nova lorque: Routledge.

Casetti, F. \& Di Chio, F. (1991). Cómo analizar un film. Barcelona: Paidós.

Chabert, G. \& Groupierre, K. (2018, julho). Le dispositif réalités impossibles: la traversée des espaces. Comunicação apresentada no Colloque International IMPEC, Corps et Ecrans, Lyon.

Charrière, M. (Realizador). (2017-2019). Hors-Cadre [Documentário-web]. Suiça: RTS y DNA Studios.

Collier, J. \& Collier, M. (1986). Visual anthropology: photography as a research method. Albuquerque: University of New Mexico Press.

Collier, J. (1995). Photography and visual anthropology. In P. Hockings (Ed.), Principles of visual anthropology (pp. 235-254). Nova lorque: Mouton de Gruyter.

Contreras, F. (2017). Estudio sobre los planteamientos teóricos y metodológicos de los estudios visuales. Arte, Individuo Y Sociedad, 29(3), 483-499. 
Cordido, I. (2010). Fundamentos iniciales de la investigación audiovisual trascendente. Revista Arbitrada de La Facultad Experimental de Arte de La Unviersidad Del Zulia, 5(8), 42-52. Retirado de https:// produccioncientificaluz.org/index.php/situarte/article/view/15985

Court, M. \& Lerner, R. (Realizadores). (2013-2019). Proyecto Quipu [Documentário-web]. Chile: Chaka Studio.

Cyrulnik, N. (2018). Méthodes visuelles. Analyse communicationnelle d'une méthode documentaire. In F. J. Herrero Gutiérrez, M. Trenta, V. Rodríguez Breijo, S. Toledano Buendía, C. E. Hernández Rodríguez \& A. I. Ardèvol Abreu (Eds.), Comunicación y música: mensajes, manifestaciones y negócios (pp. 289-305). Espanha: Sociedad Latina de Comunicación Social.

De la Peña, N., Lichtenstein, B. \& Fitzsimmons, J. (Realizadores). (2015). Across the line [Documentário-web]. EUA: Emblematic Group.

De la Torre, M. (Realizador). (2016-2018). La Primavera rosa [Documentário-web]. Espanha: Creta Producciones.

Derrida, J. \& Stiegler, B. (1998). Ecografías de la televisión. Buenos Aires: Universidad de Buens Aires.

Dickey, S. (1997). La antropología y sus contribuciones al estudio de los medios de comunicación. Revista Internacional de Ciencias Sociales, 153. Retirado de http://www.unesco.org/new/en/ social-and-human-sciences/resources/periodicals/issj-social-science/\#sdart

Dion, D. (2007). Les apports de l'anthropologie visuelle a l'etude des comportements de consommation. Recherche et Applications En Marketing, 22(1), 61-78. https://doi.org/10.1177/076737010702200104

Febrer, N. (2013). Aproximaciones teóricas en antropología visual: fundamentos metodológicos. Estudios Sobre El Mensaje Periodistico, 19[número especial], 725-734. https://doi.org/10.5209/rev_ESMP.2013. v19.42155

Flick, U. (2011). La entrevista en investigación cualitativa. Madrid: Ediciones Morata.

Flick, U. (2015). El diseño de investigación cualitativa. Madrid: Ediciones Morata.

Flores-Márquez, D. (2015). Imaginar un mundo mejor: la expresión pública de los activistas en internet. Guadalajara: Universidad Jesuita de Guadalajara.

García-Canclini, N. (2010). La sociedad sin relato: antropología y estética de la inminencia. Buenos Aires: Katz.

Gaudreault, A. \& Jost, G. (1995). El relato cinematográfico. Barcelona: Paidós Comunicación.

Geertz, C. (1992). Descripción densa: hacia una teoría interpretativa de la cultura. Barcelona: Editorial Gedisa.

Gifreu Castells, A. (2013). El documental interactivo como nuevo género audiovisual. Barcelona: Universitat Pompeu Fabra.

Gómez Cruz, E. (2012). De la cultural Kodak a la image en red. Una etnografia sobre fotografia digital. Barcelona: Editorial UOC.

Goodwin, C. (1993). Recording human interaction in natural settings. Pragmatics, 3(2), 181-209. https://doi. org/10.1075/prag.3.2.05goo

Goodwin, C. (2000). Practices of seeing: visual analysis - an ethnomethodological approach. In T. van Leeuwen \& C. Jewitt (Eds.), Handbook of visual analysis (pp. 157-182). Londres: Sage Publications.

Hine, C. (2005). Virtual methods: issues in social research on the internet. Nova lorque: Berg Publishers. 
Hine, C. (2015). Ethnography for the internet. Embedded, embodied and everyday. Londres: Bloomsbury Academic

Hockings, P. (Ed.) (1995). Principles of visual anthropology. Nova lorque: Mouton de Gruyter.

Hopkins, M. (Realizador) (2017). On the brink of famine. Urgence au sud Soudan [Filme]. Sudaõ do Sul: Frontline.

Horkheimer, M. \& Adorno, T. W. (2016). Dialéctica de la ilustración: fragmentos filosóficos. Madrid: Trotta.

Ibanez, J. (2006, março). Création d'un hypermédia virtuel et ethnologique. L'exemple d'une recherche sur les internautes suisses et français. Comunicação apresentada no Colóquio "Du cinema ethnographique à l'antropologie visuelle", Musée de l'Homme, Paris.

Ibanez, J., Chabert, G., Lamboux-Durand, A. \& Wanono, N. (2017). Applying visual methods to digital communication. Tenerife: Cuadernos Artesanos de Comunicación.

Jewitt, C. (2012). An introduction to using video for research. NCRM Working paper 03/12. Londres: Institute of Education. Retirado de http://eprints.ncrm.ac.uk/2259/4/NCRM_workingpaper_0312.pdf

Köster, C. R. (2005). Nuevos relatos audiovisuales. Hacia una definición del relato audiovisual interactivo. Revista TELOS, Cuadernos de Comunicación E Innovación, 62, 81-87.

Lallier, C. (2009). Pour une anthropologie filmée des interactions sociales. Paris: Éditions des Archives Contemporaines.

Lallier, C. (2011). L'observation filmante. Une catégorie de l'enquête ethnographique. L'Homme. Revue Française D'anthropologie, 105-130. https://doi.org/10.4000//homme.22718

Lemos, A. (2008). Mobile communication and new sense of places: a critique of spatialization in cyberculture. Galáxia, 16, 91-108. Retirado de https://revistas.pucsp.br/galaxia/article/view/1914

Mann, S. (2016). The research interview. Reflective practive and reflexivity in research precesses. Nova lorque: Palgrave Macmillan.

Mattelart, A. \& Mattelart, M. (1997). Historias de las teorías de la comunicación. Barcelona: Paidós.

Mayans i Planells, J. (2002). Género chat: o cómo la etnografía puso un pie en el ciberespacio. Barcelona: Gedisa.

Nichols, B. (2010). Introduction to documentary. Indiana: Indiana University Press.

Pauwels, L. (2000). Taking the visual turn in research and scholarly communication key issues in developing a more visually literate (social) science. Visual Sociology, 15(1), 7-14. https://doi. org/10.1080/14725860008583812

Pink, S. (2001). Doing visual ethnography. Londres: Sage Publications.

Pink, S. (2006). The future of visual anthropology: engaging the senses. Nova lorque: Routledge.

Plantinga, C. (2014). Retórica y representación en el cine de no ficción. México: Universidad Nacional Autónoma de México.

Rodrigo-Alsina, M. (1989). La construcción de la noticia. Barcelona: Paidós.

Rouch, J. (1995). The camera and man. In P. Hockings (Ed.), Principles of visual anthropology (pp. 79-98). Berlim: De Gruyter Mouton 
Rouch, J. (2003). Ciné-ethnography. Londres: University of Minnesota Press.

Ruby, J. (2000). Picturing culture: explorations of film and anthropology. Londres: The University of Chicago Press.

Sierra, I. \& Gerrit, S. (Realizadores). (2015). La Siberia [Documentário]. Colombia: $17^{\mathrm{a}}$ MIDBO.

Spiltunik, D. (1993). Anthropology and mass media. Annual Review of Anthropology, 22, 293-315. https://doi. org/10.1146/annurev.an.22.100193.001453

Stollbrock, G. (2017). Representación claroscura: una exploración audiovisual y teórica de la representación del pasado en el cine documental. Íconos: Revista de Ciencias Sociales, 59, 79-102. https://doi. org/10.17141/iconos.59.2017.2678

Turkle, S. (1997). La vida en la pantalla: la construcción de la identidad en la era de internet. Barcelona: Paidós.

Vila Guevara, A. (2017). In-between ethnography and filmmaking: field notes and rituals behind the frame. Anthropology Now, 9(1), 34-47. https://doi.org/10.1080/19428200.2017.1291821

Vila-Guevara, B. (Realizador). (2016). Belén [Documentário]. Venezuela - España: Secuencia Cero Films e Crater Producciones.

\section{NOTAS BIOGRÁFICAS}

Alba Marin Carrillo é professora do Departamento Comunicação Hipermédia da Universidade Savoie Mont Blanc, França. Qualificada como Maître de Conférence em SIC e doutorada em Comunicação pela Universidade de Sevilha e pela Comunidade Universitária Grenoble Alpes. Mestre em Comunicação e Cultura e Graduada em Jornalismo (US).

ORCID: https://orcid.org/0000-0003-0285-7086

Email:ylbacm@gmail.com; alba-maria.marin-carrillo@univ-smb.fr

Morada: Rua du Sergent Revel, Jacob-Bellecombette, 73000 Chambéry Cedex, França

Fernando Contreras Medina é Professor Titular do Departamento de Jornalismo 1, Vicedecano da Faculdade de Comunicação, Universidade de Sevilha. Doutor em Comunicação, Doutor em Filosofia e Bacharel em Belas Artes.

ORCID: https://orcid.org/0000-0003-1105-5800

Email: fmedina@us.es

Morada: Américo Vespucio, s/n, La Cartuja, Sevilla, Espanha

Submetido: 05/09/2019

Aceite: $31 / 11 / 2019$ 